University of Wollongong

Research Online

Faculty of Social Sciences - Papers (Archive) Faculty of Arts, Social Sciences \& Humanities

January 2020

\title{
A clinician's quick guide to evidence-based approaches: Narcissistic personality disorder
}

Ross M. King

Deakin University

Brin F. S Grenyer

University of Wollongong, grenyer@uow.edu.au

Clint G. Gurtman

Rita Younan

Follow this and additional works at: https://ro.uow.edu.au/sspapers

Research Online is the open access institutional repository for the University of Wollongong. For further information contact the UOW Library: research-pubs@uow.edu.au 


\section{A clinician's quick guide to evidence-based approaches: Narcissistic personality disorder}

\section{Publication Details}

King, R., Grenyer, B., Gurtman, C. \& Younan, R. (2020). A clinician's quick guide to evidence-based approaches: Narcissistic personality disorder. Clinical Psychologist, 24 (1), 91-95. 
This is the author's final submitted version. Citation: King, R.M., Grenyer, B.F.S., Gurtman, C.G., Younan, R. (2020). A clinician's quick guide to evidence-based approaches: Narcissistic personality disorder. Clinical Psychologist, 24, 91-95 https://doi.org/10.1111/cp.12214

\section{A clinician's quick guide to evidence-based approaches: Narcissistic personality disorder}

Ross M. KING ${ }^{1}$, Brin F.S. GRENYER², Clint G. GURTMAN ${ }^{1}$, and Rita YOUMAN³

${ }^{1}$ School of Psychology, Deakin University

${ }^{2}$ School of Psychology, University of Wollongong

${ }^{3}$ Schema Therapy Institute of Australia, Melbourne

\section{Correspondence}

Ross King, School of Psychology, Deakin University, Locked Bag 20001, Geelong, VIC 3220, Australia Email: rking@deakin.edu.au

\section{Introduction}

Pathological narcissism has a long history dating back 2000 years, that has evolved into contemporary clinical psychology as a trait that may require clinical attention (Grenyer, 2013). Traditionally, Narcissistic personality disorder (NPD) is one of the 10 identified personality disorders in the Diagnostic and Statistical Manual of Mental Disorders, Fifth Edition (DSM-5). An alternative trait-based model of personality disorders in DSM-5 described in Section III includes a more contemporary version of NPD. The former NPD description only describes the grandiose form characterized by a grandiose sense of self-importance, fantasies of success, power etc, a belief in one's specialness, desire for admiration, sense of entitlement, interpersonal exploitativeness, and lack of empathy. The alternative NPD also describes impairments in functioning across identity, self-direction, empathy, and intimacy and while identifying pathological personality traits of grandiosity and attention seeking (both facets of antagonism) as well as more vulnerable narcissism presentations with aspects of negative affectivity such as depressivity and anxiousness (American Psychiatric Association, 2013). (see Pincus, Dowgwillo, \& Greenberg (2016) for descriptions of 3 cases of NPD using the alternative DSM-5 model). Thus, contemporary views of pathological narcissism recognise both grandiose and vulnerable components.

\section{Existing Treatment Guidelines}

No treatment guidelines currently exist for NPD.

\section{Useful overviews for clinicians}

Ronningstam, E. \& Weinberg, I. (2013). Narcissistic personality disorder: Progress in recognition and treatment. Focus, 11, 167-177.

Caligor, E., Levy, K., Yeomans, F. (2015). Narcissistic personality disorder: Diagnostic and clinical challenges. American Journal of Psychiatry, 172, 415-422.

Roepke, S. \& Vater, A. (2014). Narcissistic personality disorder: An integrative review of recent empirical data and current definitions. Current Psychiatry Reports, 16, 445. 


\section{Evidence-based treatment manuals}

No evidence-based treatment manuals exist.

\section{Assessment}

Diagnostic interviews

- Structured Clinical Interview for DSM-5 Personality Disorders (SCID-5-PD) (First, Williams, Benjamin \& Spitzer, 2016).

- Structured Clinical Interview for DSM-5 Personality Disorders for the DSM-5 Alternate Model for Personality Disorders (SCID-5-AMPD) (First, Skodol, Bender \& Oldham, 2018).

\section{Self-report measures}

- Personality Inventory for DSM-5(PID-5) (Krueger, Derringer, Markon, Watson \& Skodol, 2013). A 220-item self-report measure of maladaptive personality traits underlying the DSM-5's alternate model for personality disorders.

- Pathological Narcissism Inventory (Pincus et al., 2009). A 52-item self-report measure of both grandiose and vulnerable narcissistic features.

- Five Factor Narcissism Inventory (Glover, Miller, Lynam, Crego \& Widiger, 2012). A 147-item selfreport measure of maladaptive variants of five factor model traits associated with vulnerable \& grandiose narcissism.

- The Millon Clinical Multiaxial Inventory-IV (MCMI-IV) (Millon, Millon, \& Grossman, 2015) is a 195item test that can assess narcissism in the context of other personality patterns in individuals undergoing psychological or psychiatric assessment or treatment

- Scale elevations on other more regularly used self-report tests can also assess certain narcissistic traits, including the MMPI-2-RF (Ben-Porath, 2012); The Personality Assessment Inventory (PAI) (Morey, 2007) and Paulhus Deception Scales (PDS) (Paulhus, 1999).

\section{Take home messages about treatment}

- Evidence-based treatment for NPD is limited. Most studies of personality disorder or borderline personality disorder have included patients with narcissistic traits, but no study has recruited a NPD-only group. Most treatment recommendations therefore rely on evidence from studies with mixed personality feature participants.

- No randomized control trials have been conducted. A multicentre effectiveness trial of schema therapy versus clarification-oriented psychotherapy or treatment as usual for personality disorders had only 9 NPD clients so no conclusions can be drawn (Bamelis, Evers, Spinhoven \& Arntz, 2014).

- Psychodynamic treatment approaches to NPD developed in the 1970s include Kernberg's Transference-focused psychotherapy (Stern, Yeomans, Diamond, \& Kernberg, 2013) and Kohut's self-psychology approach (Liberman, 2013).

- Cognitive-behavioral therapy approaches to treating NPD have been described (Beck, Freeman \& associates, 1990; Beck, Freeman, Davis and associates, 2004; Freeman \& Fox, 2013; Newman \& Ratto, 2004; Sperry \& Sperry, 2016).

- A schema therapy protocol for NPD is described by Young, Klosko and Weishaar (2003) and has been more fully developed by Wendy Behary and colleagues (Behary \& Davis, 2016; Behary \& Dieckmann, 2013). 
- A recent constructivist therapy, metacognitive interpersonal therapy, focuses on NPD client's intellectualizing narrative style, difficulties in recognizing inner states and emotional triggers, empathy and seeing other's perspective and maladaptive interpersonal schemas (Di Maggio \& Attina, 2012; DiMaggio et al., 2014; Dimaggio, Montano, Popolo, \& Salvatore, 2015).

- NPD clients rarely seek help for therapy for their narcissism; they are more likely to present as a result of a narcissistic injury (breakdown in a relationship, failure to gain a promotion) that results in depression, substance abuse etc or due to an ultimatum from a spouse or employer (Ronningstam \& Weinberg, 2013).

- Alliance building (Ronningstam, 2012) and transference and countertransference reactions (Gabbard, 2009) are major challenges in therapeutic relationship. There is a need to set limits and boundaries to manage the client's grandiosity and entitlement. Dropout, however, is as high as $40 \%$, especially when any external third party's (e.g., spouse) leverage diminishes (Behary \& Dieckmann, 2011).

- Suicidality is a significant risk requiring careful assessment (Ronningstam \& Weinberg, 2013; Ronningstam, Weinberg, Goldblatt, Schechter, \& Herbstman, 2018).

\section{New and emerging developments}

- The assessment and understanding of personality disorder is changing. The International Classification of Diseases (ICD-11) has moved to describing a single disorder - personality disorder with an understanding of differential traits in the individual described dimensionally (Grenyer, 2017). Personality dysfunction in the ICD-11 is fundamentally thought to be due to two challenges: diffuse self-identity (e.g. problems in identity, understanding the self, and poor goal setting or direction in life) and impaired interpersonal functioning (e.g. difficulties understanding others views, impaired empathy, poor relationship boundaries) (Tyrer et al., 2011). On this basis NPD turns around a fragile sense of self (compensated by aggrandisement) or poor interpersonal functioning (often but not aways associated with exploitative behaviours). "Vulnerable" narcissism functions to also bolster poor self-esteem through excessive attention seeking.

An informant version of the Five-Factor Narcissism Inventory found good convergence between self and informant ratings on grandiose features (e.g., extraversion) than vulnerable features (e.g, neuroticism), possiblity due to the internal and less observable nature of the latter. Oltmanns, J.R., Crego, C., \& Widiger T.G. (2018). Informant assessment: The Informant Five-Factor Narcissism Inventory. Psychological Assessment, 30, 31-42. http://dx.doi.org/10.1037/pas0000487

Recent brain imaging research (Nenadic et al., 2015; Schulze et al., 2013) comparing small samples of NPD individuals with controls describe grey matter deficits in the middle frontal gyri, middle prefrontal gyrus, and cingulate cortices. Right prefrontal \& bilateral medial prefrontal pathology may be linked to emotional regulation difficulties or cognitive deficits in attribution or coping while the anterior insular is linked to empathy.

- A recent systematic review showed a link between narcissism and aggression and violence in both nonclinical and clinical samples Lambe, S. Hamilton-Giachritsis, C., Garner, E. \& Walker, J. (2018). The role of narcissism in aggression and violence: A systematic review. Trauma, Violence, \& Abuse, 19, 209-230. DOI: 10.1177/1524838016650190. Similarly, a meta- analysis support the association of narcissism with aggression in response to provocation, especially in those with high entitlement or vulnerable narcissism features. Rasmussen, K. (2016). Entitled vengeance: A meta-analysis 
relating narcissism to provoked aggression. Aggressive Behavior, 42, 362-379. DOI:

10.1002/ab.21632

- The negative interpersonal impact of NPD individuals on others has led to a proliferation of selfhelp books for those involved in romantic (Behary, 2013; Malkin, 2013; McBride, 2015) parentchild (Brown, 2008; McBride, 2008) and work relationships (DuBrin, 2012; Eddy \& DiStefano, 2015; Malkin, 2015) with NPD individuals.

- Research on test profile configurations (e.g., MMPI-2-RF) can assist the self-report assessment of NPD (e.g. Anderson et al., 2015; Sellbom \& Smith 2017; Sellbom et al., 2014).

\section{Useful websites and online resources}

Fact sheet on Narcissistic Personality Disorder https://www.projectairstrategy.org/content/groups/public/@web/@projectair/documents/doc/uow243934.pdf

Mayo Clinic https://www.mayoclinic.org/diseases-conditions/narcissistic-personality-disorder/symptomscauses/syc-20366662

Professor Ken Levy on Pathological Narcissm:

https://www.youtube.com/watch?v=ueqbbskMBml

Webinar - McLean Hospital, Harvard University (Elsa Ronningstam) https://www.youtube.com/watch?v=DpHcNMFcEtA

\section{References}

Anderson, J.L., Sellbom, M., Pymont, C., Smid, W., De Saeger, H. \& Kamphuis, J.H. (2015). Measurement of DSM-5 Section II Personality Disorder Constructs Using the MMPI-2-RF in Clinical and Forensic Samples. Psychological Assessment, 27, 786-800.

https://doi.org/10.1037/pas0000103

Bamelis, L.L., Evers, S.M., Spinhoven, P., \& Arntz, A. (2014). Results of a multicenter randomized controlled trial of the clinical effectiveness of schema therapy for personality disorders. American Journal of Psychiatry, 171, 305-322

https://doi.org/10.1186/1471-2458-12-75

Beck, A.T., Freeman, A. \& associates. (1990). Cognitive therapy of personality disorders. New York: Guilford.

Beck, A.T., Freeman, A., Davis, D. \& associates. (2004). Cognitive therapy of personality disorders $\left(2^{\text {nd }}\right.$. Ed). New York: Guilford.

Behary, W. (2013). Disarming the narcissist ( $2^{\text {nd }}$ ed.). Oakland, CA: New Harbinger. 
Behary, W. \& Dieckmann, E. (2011). Schema therapy for narcissism: The art of empathic confrontation, limit setting, and leverage. In W.K. Campbell \& J.D. Miller (Eds.) Handbook of narcissism and narcissistic personality disorder. New York: Wiley.

Behary, W. \& Dieckmann, E. (2013). Schema therapy for pathological narcissism. In J. S. Ogrodniczuk (Ed.) Understanding and treating pathological narcissism. Washington, DC: American Psychological Association.

Behary, W. \& Davis, D. (2015). Narcissistic personality disorder. In A.T. Beck, D. Davis, \& A. Freeman (Eds.), Cognitive therapy of personality disorders ( $3^{\text {rd }}$. Ed). New York: Guilford.

Ben-Porath, Y.S. (2012). Interpreting the MMPI-2-RF. Minneapolis: University of Minnesota Press.

Brown, N.W. (2008). Children of the self-absorbed: A grown-ups guide to getting over narcissistic parents ( $2^{\text {nd }}$ ed.) Oakland, CA: New Harbinger.

Day N.J.S., Bourke M.E., Townsend M.L., \& Grenyer B.F.S. (2019). Pathological narcissism: A study of burden on partners and family. Journal of Personality Disorders. e-View Ahead of Print. https://doi.org/10.1521/pedi_2019_33_413

Dimaggio, G. \& Attinà, G. (2012). Metacognitive interpersonal therapy for narcissistic personality disorder and associated perfectionism. Journal of Clinical Psychology, 68, 922934. DOI: $10.1002 /$ jclp.21896

Dimaggio, G., Montano, A., Popolo, R., \& Salvatore, G. (2015). Metacognitive interpersonal therapy for personality disorders: A treatment manual. London: Routledge.

Dimaggio, G., Valeri, S., Salvatore, G., Popolo, R., Montano, A., \& Ottavi, P. (2014). Adopting metacognitive interpersonal therapy to treat narcissistic personality disorder with somatization. Journal of Contemporary Psychotherapy, 44, 85-95. DOI 10.1007/s10879-0139254-8

DuBrin A. (2012). Narcissism in the workplace. Cheltenham: Edward Elgar Publishing.

Eddy, B., \& DiStefano, L. (2015). It's all your fault at work: Managing narcissists and other high-conflict people. Scottsdale AZ: Unhooked Books.

First, M.B., Skodol, A.E., Bender, D.S., \& Oldham, J.M. (2018). Structured clinical interview for the DSM-5 alternative model for personality disorders. Arlington, VA: American Psychiatric Publishing.

First, M.B., Williams, J. B., Benjamin, L.S., \& Spitzer, R.L. (2016). Structured Clinical Interview for DSM-5 Personality Disorders (SCID-5-PD). Arlington, VA: American Psychiatric Publishing.

Freeman, A. \& Fox, S. (2013). Cognitive behavioural perspectives on the theory and treatment of the narcissistic character. In J.S. Ogrodniczuk (Ed.), Understanding and treating pathological narcissism. Washington, DC: American Psychological Association. 
Gabbard, G.O. (2009). Transference and countertransference developments in the treatment of narcissistic personality disorder. Psychiatric Annals, 39, $129-136$. http://dx.doi.org/10.3928/00485713-20090301-03

Glover, N., Miller, J.D., Lynam, D.R., Crego, C. \& Widiger, T. (2012). The Five-Factor Narcissism Inventory: A five-factor measure of narcissistic personality traits. Journal of Personality Assessment, 94, 500-512. DOI: 10.1080/00223891.2012.670680

Grenyer, B.F. (2013). Historical overview of pathological narcissism. In J.S. Ogrodniczuk (Ed.), Understanding and treating pathological narcissism. Washington, DC: American Psychological Association.

Grenyer B.F.S, (2018). Revising the diagnosis of personality disorder: Can it be single, clinical and factorial? Australian and New Zealand Journal of Psychiatry 52(2): 202-203. doi: 10.1177/0004867417741984. Epub 2017 Nov 16

Krueger,R.F., Derringer, J., Markon, K.E., Watson, D. \& Skodol, A.E. (2013) Personality Inventory for DSM-5(PID-5)- Adult. American Psychiatric Association.

Liberman, M.D. (2013). Kohut's self-psychology approach to treating pathological narcissism. In J.S. Ogrodniczuk (Ed.), Understanding and treating pathological narcissism. Washington, DC: American Psychological Association.

Malkin, C. (2015). Rethinking narcissism: The bad-and surprising good-about feeling special. New York: Harper-Wave.

McBride, K. (2008). Will I ever be good enough? Healing the daughters of narcissistic mothers. New York: Atria.

McBride, K. (2015). Will I ever be free of you? How to navigate a high-conflict divorce from a narcissist and heal your family. New York: Atria.

Millon, T., Grossman, S., \& Millon, C. (2015). Millon Clinical Multiaxial Inventory-IV. Minneapolis: Pearson Assessments.

Morey, L. C. (2007). Personality Assessment Inventory professional manual (2nd ed.). Lutz, FL: Psychological Assessment Resources.

Nenadic, I., Güllmar, D., Dietzek, M., Langbein, K., Steinke, J., \& Gaser, C. (2015). Brain structure in narcissistic personality disorder: a VBM and DTI pilot study. Psychiatry Research: Neuroimaging, 231, 184-186. http://dx.doi.org/10.1016/j.pscychresns.2014.11.001

Newman, C.F., \& Ratto, C.L. (2004). Narcissistic personality disorder. In M. Reinecke \& D. Clark (eds). Cognitive therapy across the lifespan. Cambridge University Press.

Paulhus, D. L. (1999). Paulhus Deception Scales (PDS): The Balanced Inventory of Desirable Responding-7 (User's manual). Toronto, Ontario, Canada: Multi-Health Systems. 
Pincus, A.L., Ansell, E.B., Pimentel, C.A., Cain, N.M., Wright, A.G., \& Levy, K.N. (2009). Initial construction and validation of the Pathological Narcissism Inventory. Psychological Assessment, 21, 365-379. DOI: 10.1037/a0016530

Ronningstam, E. (2012). Alliance building and narcissistic personality disorders. Journal of Clinical Psychology, 68, 943-953. DOI: 10.1002/jclp.21898

Ronningstam, E. \& Weinberg, I. (2013). Narcissistic personality disorder: Progress in recognition and treatment. Focus, 11, 167-177. https://doi.org/10.1176/appi.focus.11.2.167

Ronningstam, E., Weinberg, I. Goldblatt, M., Schechter, M. \& Herbstman, B. (2018). Suicide and self-regulation in narcissistic personality disorder. Psychodynamic Psychotherapy, 46, 491-510.

Schulze, L., Dziobek, I., Vater, A., Heekkeren, H., Bajouj, M., Renneberg, B., Heuser, I., \& Roepke, S. (2013). Gray matter abnormalities in patients with narcissistic personality disorder. Journal of Psychiatric Research, 47, 1363-1369.

http://dx.doi.org/10.1016/j.jpsychires.2013.05.017

Sellbom M \& Smith A. 2017. Assessment of DSM-5 Section II personality disorders with the MMPI-2-RF in a nonclinical sample. Journal of Personality Assessment,99,384-397. https://doi.org/10.1080/00223891.2016.1242074

Sellbom, M., Smid, W., De Saeger, H., Smit, N.,\& Kamphuis, J. H. (2014). Mapping the personality psychopathology five domains onto DSM-IV personality disorders in Dutch clinical and forensic samples: Implications for the DSM-5. Journal of Personality Assessment, 96, 185-191. DOI:10.1080/00223891.2013.825625

Sperry, L., \& Sperry, J. (2016). Cognitive behavior therapy of DSM-5 personality disorders: Assessment, case conceptualization, and treatment ( $3^{\text {rd }}$ ed.) New York: Routledge.

Stern, B.L., Yeomans, F., Diamond, D., \& Kernberg, O. (2013). Transference-focused psychotherapy for narcissistic personality. In J.S. Ogrodniczuk (Ed.), Understanding and treating pathological narcissism. Washington, DC: American Psychological Association.

Tyrer, P., Crawford, M., Mulder, R., Blashfield, R., Farnam, A., Fossati, A., Kim, Y.R., Koldobsky, N., Lecic-Tosevski, D., Ndetei, D. \& Swales, M. (2011). The rationale for the reclassification of personality disorder in the 11th revision of the International Classification of Diseases (ICD-11). Personality and Mental Health, 5(4), pp.246-259.

Young, J.E., Klosko, J.S., \& Weishaar, M.E. (2003). Schema therapy: A practitioner's guide. New York: Guilford. 